\title{
A new sociological imperative: Towards engaging with pre- implantation genetic diagnosis
}

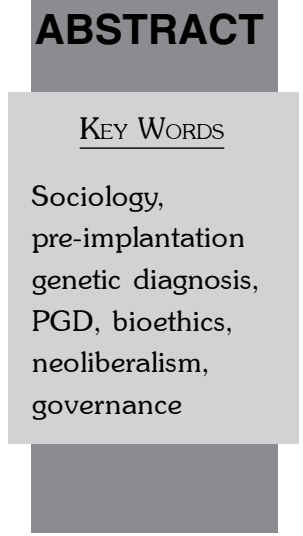

Pre-implantation genetic diagnosis (PGD) is a controversial technology in which human embryos in vitro are genetically screened (via cell biopsy) prior to selection and transfer to the womb. A review of the non-sociological literature dealing with PGD reveals a preoccupation with risk. Risk in this context is framed primarily in terms of an ethical concern focussing on the rights of the individual. Thus PGD is framed as a potential risk to individual rights. What is also evident is this use of the concept of risk obscures broader social dimensions such as choice and access. While some sociologists have located debates about PGD within a risk framework, others have drawn upon issues such as choice and responsibility. These varied positions are evident in the dissonance between lay perspectives and expert positions. I propose a number of questions about $P G D$ which require further sociological attention.

\footnotetext{
Received 30 November 2006 Accepted 8 February 2007
}

\begin{tabular}{|c|}
\hline Kellie Brandenburg \\
School of Sociology and Social Work \\
University of Tasmania \\
Australia \\
\hline
\end{tabular}

\section{Introduction}

$\mathrm{P}$ e-implantation genetic diagnosis (PGD) is one of a number of new reproductive/ genetics technologies which have emerged since IVF became widely available. While new reproductive technologies in general have been the subject of sustained sociological interest, PGD initially attracted the attention of scholars from disciplinary backgrounds as diverse as anthropology, ethics, law and government. This is despite PGD acting as a locus for a number of key sociological concerns. In addition to the ontological and epistemological concerns associated with technologies such as IVF and prenatal testing, PGD as a pre-implantation genetic technology intersects with these concerns to offer distinct avenues for sociological exploration. Recently, sociologists have begun this task, with preliminary investigations focusing on the role and impact of expert actors such as geneticists and medical practitioners; on the ways individuals understand and experience their participation in PGD; and on the way PGD is constructed in the media.

\section{What is PGD?}

Pre-implantation genetic diagnosis (PGD) is a human reproductive technology in which human embryos in vitro are genetically screened (via cell biopsy) prior to selection and transfer to the womb (Bickerstaff et al. 2001; Braude et al. 2002). PGD can be used for sex selection (for social or medical reasons), to improve IVF success rates and screen embryos for chromosomal abnormalities and inherited genetic diseases (Robertson 2003). It can also be used to screen embryos in order to produce a child who is a tissue match (and donor) for an existing child (Bellamy 2005; Gavaghan 2003). Recent indications suggest PGD may soon be used to screen for susceptibility to adult-onset illnesses such as cancer and Alzheimer's disease 
(Robertson 2003:213; Zeiler 2004:177). PGD differs from other forms of prenatal testing because it takes place prior to implantation of the embryo in the womb thus avoiding termination of pregnancy (Cameron and Williamson 2003).

PGD has become the subject of public debate in Australia and overseas. As Robertson (2003:213) states, 'PGD is ethically controversial because it involves the screening and likely destruction of embryos, and the selection of offspring on the basis of expected traits'. What makes PGD sociologically interesting is the ways these ethical concerns intersect with contemporary social ideas about choice, autonomy, risk and responsibility. Drawing on the work of Bunton and Petersen (2005; Petersen 2006), I argue the concepts of ethics and ethical risk are being drawn upon to justify the deployment of social judgements in the context of PGD.

\section{Perspectives on PGD}

A review of the non-sociological literature dealing with PGD reveals a preoccupation with risk. Risk in this context is framed primarily in terms of an ethical concern with the rights of the individual. Thus PGD is framed as a potential risk to individual rights. Some of these discussions have canvassed the ontological status of the preimplantation embryo (Krones et al. 2006; Polkinghorne 2004), while others have explored the contradictions inherent in a rights discourse in which the rights of the parent, the rights of the (putative) child, and the rights of the broader community may be seen as incompatible (Brock 2005; Parker 2000; Watt 2004; Zeiler 2004). Petersen (2005) explores the implications of PGD for the future of individuals living with disabilities, as expressed in the 'slippery slope' argument. Clinicians Cameron and Williamson (2003) have debated the ethical distinction between PGD and abortion. They concluded that overall PGD is ethically preferable, arguing the choice between an affected and unaffected embryo is ethically neutral; PGD is both less invasive for the woman, and avoids disrupting the relationship between mother and embryo; and is ethically preferable because rather than actively 'killing' a foetus, in
PGD embryos are 'allowed to die' (Cameron and Williamson 2003).

A particularly spirited debate centres on the use of PGD to select embryos for so called 'nonmedical traits'. Such discussions have addressed PGD tests which are currently available for sex selection (Jones 2001; Reame 2001; Rhodes 2001; Robertson 2001, 2003; Scully et al. 2006), and hypothetical scenarios such as PGD screening for homosexuality or musical talent, for which tests are not currently available (Ashcroft 2003; Rixecker 2002; Savulescu 2001). Theologians concerned with the ethics of PGD have discussed both sex-selection (Habgood 2003) and tissue-matching (Bellamy 2005) from a Christian philosophical perspective. Ethical risk is also associated with decisions surrounding the use of PGD to produce a tissuematched sibling (Gavaghan 2003).

\section{Sociological perspectives on (ethical) risk and PGD}

Sociology is well-placed to interrogate how the concept of risk is used in contemporary society. Beck (1992) and Giddens (1990, 1991) have written extensively on the significance of risk in reflexive/late modernity. Lupton (1999:104) states that according to Beck's 'risk society' thesis, 'reflexive awareness and concern about risk pervades modern sensibilities'. She argues a Foucauldian governmentality approach reveals this pervasive sense of risk and contributes to the conceptualisation of the 'autonomous, selfregulating moral agent' who, apparently without coercion, behaves according to broadly accepted risk positions (Lupton 1999:104, 105-113). Kerr and Cunningham-Burley (2000) have also drawn on Beck and Giddens to theorise the position of the new human genetics in contemporary society. They argue the new human genetics are highly characteristic of reflexive modernity and the rhetoric of risk (Kerr and Cunningham-Burley 2000:284). Their analysis suggests the practices of the new human genetics, book-ended as they are by notions of autonomous choice on the one hand, and individual responsibility on the other, represent the embodiment of the often contradictory conditions of reflexive modernity 
(Kerr and Cunningham-Burley 2000:284-286). While Kerr and Cunningham-Burley (2000:296298) raise concerns about the potential eugenicist implications of the new human genetics, they also point out that sociology has the potential to disrupt the dominant discourses of risk, responsibility and choice which underpin such concerns.

Concern with eugenic risk is also apparent in a monograph about PGD entitled The Future of Human Nature (Habermas 2003). Habermas argues PGD undermines our basic humanity and has far-reaching implications for the instrumentalisation of human life. As reviewers have pointed out, Habermas' perspective reflects the total prohibition of PGD in Germany with its associations with Nazi eugenics programs (Domingues 2004; Kavoulaksos 2004; Scambler 2005). While Habermas' disciplinary origins are in sociology, this contribution offers little explication for the place of $\mathrm{PGD}$ in social relations and behaviour. Habermas' position is echoed in that of popular futurist Fukuyama (2003:7) who argues "the most significant threat posed by contemporary biotechnology is the possibility that it will alter human nature and thereby move us into a 'posthuman' stage of history'. Franklin and Roberts (2006:32-39) argue these fears result from muddied thinking about the concept of 'human nature' as well as an inability to distinguish between the desire of parents to provide the best possible start for their children and the design of children in and of itself.

An alternative perspective on PGD is proposed by Foucauldian sociologists. Rose (2005:7) argues the 'troubled discourse' of writers such as Habermas and Fukuyama is built upon a dystopic interpretation of 'overstated claims' about a dire future. In contrast, Rose (2005:12) draws on Rapp (1999) to label PGD participants as 'ethical pioneers' and lauds them for engaging with a complex array of social, technical, ethical and practical demands. Petersen (2006:488) agrees, arguing for individuals facing decisions about PGD, 'issues of identity, risk and responsibility for others are likely to take on heightened significance'. Petersen (2006:495) argues perspectives drawing on an ethical framework are inherently unable to make sense of the complex and distinctive questions associated with PGD and other forms of human genetic technology, while sociology as a critical discipline is able to offer a more sophisticated examination of both the "normative and social justice implications' attached to these processes.

Bunton and Petersen (2005) suggest the work of Foucault offers a number of analytical techniques and conceptual tools for understanding the ways that PGD (amongst other genetics technologies) embodies contemporary surveillance and risk discourses. In particular they argue Foucault's governmentality thesis provides a framework for understanding PGD in terms of neoliberal rationality and governance regimes (Bunton and Petersen 2005). They claim this approach allows for a more critical exploration of questions 'often left unexplored by recent research on ethical, legal and social issues' associated with PGD and other new human genetics technologies (2005:2). Thus Bunton and Petersen (2005:9) propose a sociological scholarship of the new human genetics technologies which unpacks what they describe as the intimate relationship between ethical considerations and governance'. Bunton and Petersen (2005) draw on Foucault's concepts of biopower and governmentality to argue concerns about the ethics of genetics which are enacted at the individual level are linked to neoliberal discourses of risk and responsibility operating at a population level.

A number of scholars, some from outside sociology, have offered a response to Bunton and Petersen. They have explored the social construction of ethics and ethical concerns about genetics (Jallinoja 2005; Helen 2005); genetic screening as a form of population governance (Poutanen 2005); genetic testing as an embodiment of risk and responsibility discourses (Polzer 2005; Lemke 2005); genetic surveillance and the gendered body (Ettore 2005); notions of choice in genetic testing and how these notions are applied to individuals living with disabilities (Ward 2005); socio-economic status and access to genetics technologies (Kelly 2005); genetic essentialism (Willis 2005; Herbert 2005); and 
regulatory aspects of genetics (Gottweis 2005). While none of these studies specifically investigated PGD, each of these aspects of genetics is relevant to the sociological study of PGD. These scholars explore the ways neoliberal ideas about choice, responsibility, risk and autonomy are both reinforced and confounded in the context of new human genetics technologies.

\section{Access to PGD}

Further to these concerns, Petersen (2006:495) has called for sociologists to focus on "the question of who benefits and who is disadvantaged by the use of particular technologies'. I argue we should also be asking who has access to PGD and who controls access to PGD. If PGD can be conceptualised as a responsible choice made by autonomous individuals in the context of genetic risk, then regulation of access and the socially determined basis for decisions about access become key considerations.

Some sociologists are already partially exploring these questions, by focussing, for example, on the role of experts as gatekeepers to the technology. Pilnick (2002) offers some insight into the way the genetic counselling agenda is not only controlled by the counsellor in the role of expert, but also by other family members who become additional clients, and who may or may not have the same interests as the primary client. These findings echo anthropological work suggesting the new human genetics serves to reverse the contemporary tendency towards families of choice and (re)positions individuals firmly into their biological family (Finkler et al. 2003; Rapp et al. 2001). These findings were also confirmed in a study of PGD 'experts' from four different European countries (Ettore 1999). Ettore found expert participants used normative judgements to shape ostensibly neutral clinical decisions and indeed the whole direction of treatment available to both individuals and families. Experts mobilised 'stories' about families in order to make sense of the complicated and often lengthy process of assembling genetic information, drawing on a range of ideological strategies for justifying this approach. These strategies ranged from adherence to a strict separation of the science of genetics from the social context in which it is enacted, to a countervailing adherence to the conventions of bioethical practice which is seen to act as a kind of moral safety net for workers engaged in (what they regard as) ethically challenging practices.

The role played by experts deploying normative and social judgement strategies is clearly articulated in a study of expert workers in PGD clinics in England (Ehrich et al. 2006). PGD clinics in England are located in a regulatory environment explicitly requiring potential participants in PGD to be screened with a view to the welfare of the child'. This assessment process weighs a variety of social, economic, and medical factors and involves investigations with participants' general practitioners and with relevant social welfare authorities. The findings of this study suggest this regulatory regime legitimates and gives authority to social judgements made in the PGD clinic. Writers have focussed on the 'welfare of the child' concept and the ethical dilemma this poses in relation to the potential for children to be born with a disability (Lavery 2004; Shakespeare 1998). The concept of the 'welfare of the child' remains only partially explored and raises a number of questions for sociologists. How is the 'welfare of the child' currently defined in law and in practice? What are the social justice implications of these definitions? What evidence is there that the focus on the 'welfare of the child' produces better outcomes for children conceived as a result of PGD?

What is absent in sociological discussions about access to PGD is a clear articulation of exactly who does not have access to PGD and why that might be so. For example, in Franklin and Roberts' (2006) extensive ethnography, a sample consisting of 23 apparently heterosexual, coupled, individuals are interviewed about their participation in PGD. The apparent absence of individuals or couples who do not fit into this hetero-normative model is significant and yet unaddressed. It is unclear whether this absence is because single women and non-heterosexual couples are specifically prohibited from participation in PGD, or if some other barrier to 
access is in place (or perhaps they were simply absent from this sample). This absence is all the more significant given Franklin and Roberts' (2006:19) clear approbation for the relevant regulatory authority (the Human Fertilisation and Embryology Authority) and what they claim is its 'sociological thinking' approach to regulating PGD. Franklin and Roberts (2006:135) point out the clinic in which they conducted their research has an approximately 50\% attrition rate following initial consultation, a phenomena which is entirely unexplored in this work or elsewhere. This again emphasises the need to explore the question of access in more detail and with a view to a more complete understanding of both manifest and latent barriers to participation.

\section{PGD as parental responsibility}

Chen and Schiffman (2000) interviewed individuals living with a variety of physical disabilities and found participants did not view prenatal screening as eugenicist. Participants understood prenatal genetic screening as a tool to allow them to exercise parental responsibility by avoiding passing on genetic disease to their children (Chen and Schiffman 2000). These findings are consistent with those of Roberts and Franklin (2004; Franklin and Roberts 2006). They found PGD consumers view the idea that undergoing PGD is a 'choice' with ambivalence. Participants who undertook PGD in order to prevent the conception of a child who will experience a severe or fatal illness argued passionately that in this context PGD is not a 'choice' but a 'necessity' (Roberts and Franklin 2004:288). The decision to undertake PGD is made knowing it excludes participants from pursuing alternative pathways to parenthood (in Britain, as in Australia, prospective adoptive parents are precluded from participation in assisted reproductive technology) and the attendant disruption to other life course processes such as pursuit of a demanding career (Roberts and Franklin 2004:290-291). Roberts and Franklin (2004:288-289; 2006:107-131) highlight the complex decision-making processes undertaken by PGD consumers and the way in which participants frame these processes in terms of parental responsibility.

\section{PGD in the media}

In light of these findings it is unsurprising participants expressed anger and resentment towards media depictions of PGD which rely on the 'designer baby' trope (Roberts and Franklin 2004:289). Gilding (2002:7) argues what he calls 'genetic engineering' is likely to become so ubiquitous that the expression 'designer babies' will become passé. A number of studies have explored representations of human genetics in the print news media. Prominent amongst these has been the work of Peter Conrad. Conrad (1997:142) uses a social constructionist approach to demonstrate that genetic explanations for social problems are gaining currency due to their apparent ability to simplify complex issues: 'identifying specific genes seems so much neater than complex, messy, epidemiological and social analyses'. Conrad (1997:150) argues when genetic explanations are combined with the media's tendency to oversimplify complex issues, the result is genetics becomes privileged in the public discourse about social problems. Conrad (1997:150) suggests this process could see sociology marginalised by other disciplines in discussions of social problems, and there is some evidence of this in the way relatively unsophisticated notions of ethics and risk have been deployed by disciplines other than sociology in debates about PGD.

Conrad pioneered the sociological study of PGD in the media, exploring three media debates about the potential application of PGD: alcoholism (Conrad and Weinberg 1996, 1997), homosexuality (1997), and 'race' and intelligence (1997). Since then, several studies have identified the use of metaphor as a key element in news reporting of human genetics (Condit 1999; Petersen 2001; Nerlich et al. 2003; Knudsen 2005; Petersen et al. 2005). While most of these studies used discourse and content analysis to identify discursive strategies such as metaphor (Petersen 2001; Nerlich et al. 2003; Petersen et al. 2005), Condit (1999:171-172) conducted a study in which participants were exposed to 
news articles containing different metaphors (the 'lottery' and 'blueprint' metaphors). The findings from this study suggest while the use of different metaphors results in differing interpretations by readers, readers' overall interpretations rely on the "broader ideologies" within which metaphors are located (Condit 1999:175). Condit (1999:176) argues her findings suggest future studies should explore the ways different subject positions are produced (and privileged) within media debates about human genetics and how this shapes the overall discourse. In this way, Condit (1999:178) moves beyond Conrad's findings about genetic reductionism to expand sociology's task and to remind us 'the lay public is not the dupe of anyone - not the media nor scientists nor politicians'.

Content and discourse analyses of print news media such as those of Petersen (2001), Nerlich et al. (2003), and Petersen et al. (2005), provide evidence of the way the media can be seen to construct the public debate surrounding human genetics. Lay resistance to this process, as highlighted by Condit (1999:178), is evident in letters to the editor in which the writers demonstrate a range of attitudes towards PGD differing from the broadly dystopic or negative positions contained in the news stories to which they are responding (Petersen et al. 2005:349). These studies are important in providing an empirical foundation for future research which needs to explore beyond how human genetics is produced in the news media, to find out why it is produced in that way, and by whom it is produced.

\section{Future directions for the sociology of PGD}

Media and scientific discourses surrounding the broader human genetics project have been mostly positive (Petersen 2006:482). There are high expectations within the community that genetic innovations will revolutionise both preventative health care and medical treatment (Petersen 2006:482). Petersen (2006:485) has argued the popularity of genetic discourses is linked to dominant neoliberal discourses such as those associated with individualism and responsibility. It is telling that PGD differs from the broader human genetics discourse in that both media and initial scholarly engagement have been characterised by mostly negative perspectives such as those expressed in the 'designer baby' and 'slippery slope' arguments. In my view, what distinguishes PGD from other human genetics technologies is that it is also a reproductive technology. That is, it can be seen as analogous with other gendered technologies such as IVF, which have been shown to generate a host of responses masking a broader concern with controlling women's reproductive agency and autonomy. As Petersen (2006:488) points out, women take primary responsibility for controlling genetic risk within their families and may engage with technologies such as PGD in response to this imperative. In the same way women are subject to discourses which are drawn upon to define who deserves access to IVF (Smith 2003), I argue women who engage with PGD are subject to social judgements which are justified by an ethical concern with risk. This is seen (for example) in discussions about 'designer babies' which raise the spectre of commodification of children, regardless of evidence showing individuals engage in PGD in order to prevent their children being born with a fatal or severe illness (as opposed to wanting a child with blonde hair or musical aptitude). The sociological perspective which revealed the gendered ideologies at work in IVF (Albury 1999) is wellplaced to explore the meanings and patterns of behaviour associated with PGD. Sociology is a critical discipline which seeks to interrogate the taken-for-granted assumptions informing behaviour. A sociological approach to PGD can therefore be readily contrasted with approaches which rely on these same assumptions.

Within the existing sociological literature regarding $\mathrm{PGD}$ can be seen both a direction for future studies and some gaps which remain to be addressed. Many of the studies discussed here are concerned with discourses such as risk, responsibility, choice, and autonomy. Not only do these concerns represent a contemporary preoccupation on the part of individuals living under conditions of neoliberalism, they also provide a link to the Foucauldian research framework within which 
future investigations may be situated. A Foucauldian perspective aims to reveal the underlying ideologies at work in patterns of social relations and who benefits from these configurations. Such a perspective therefore provides the researcher with an opportunity to destabilise some of the ideas and practices evident in PGD and allows for multiple understandings of these.

A number of areas remain unexplored or only partially articulated in the existing sociological literature on PGD. As discussed earlier, issues relating to access need further sociological exploration. We do not know how regulatory and policy regimes explicitly shape decisions about PGD from the point of view of the PGD consumer. Another potential area of future study includes investigations into where and how PGD participants obtain their understanding of PGD, and how this information is transformed into meaning and action. In less than a decade, researchers will be able to interview individuals conceived as a result of PGD.

\section{Conclusion}

I have canvassed contributions from sources drawing on anthropological, clinical, ethical and legal disciplinary perspectives. This literature reveals a preoccupation with rights: the rights of the parent, of the unborn, and of society. This concern with rights has been framed within an ethical discourse of risk. Some writers have also pointed to issues relating to responsibility, that is, PGD as an exercise in parental responsibility. This is a direction which has attracted sociological interest, with sociologists working within a number of different methodological approaches finding PGD consumers engage with a confronting array of issues and challenges in order to prevent their children being born with a severe or fatal illness. There is evidence the lay public also understands PGD to be a more complex issue than suggested by 'designer baby' headlines and dystopic predictions. A Foucauldian perspective has been proposed as a framework for exploring these diverse positions. Such a framework has been used to understand how discourses of risk and responsibility mediate action and meaning in the new human genetics generally. I have proposed a number of avenues for further sociological research. While sociology was relatively late to engage with $\mathrm{PGD}$, it offers much potential to provide a critical perspective on this novel and confronting technology.

\section{Acknowledgements}

The author wishes to thank the anonymous reviewers and the editor for their contributions which have greatly improved this article, and Dr Karen Willis for her tireless support, advice and encouragement.

\section{References}

Albury, R. (1999) The Politics of Reproduction: Beyond the Slogans Allen and Unwin: St Leonards.

Ashcroft, R. (2003) 'Bach to the future: Response to "Extending pre-implantation genetic diagnosis: Medical and non-medical uses"' Journal of Medical Ethics 29:217-219.

Beck, U. (1992) Risk Society: Towards a New Modernity Sage: London.

Bellamy, S. (2005) 'Lives to save lives - the ethics of tissue typing' Human Fertility 8(1):5-11.

Bickerstaff, H.; Flinter, F.; Toh Yeong, C. and Braude, P. (2001) 'Clinical application of preimplantation genetic diagnosis' Human Fertility 4:24-30.

Braude, P.; Pickering, S.; Flinter, F. and Mackie Olgivie, C. (2002) 'Pre-implantation genetic diagnosis' Nature Reviews 3:941-953.

Brock, D. (2005) 'Shaping future children: Parental rights and societal interests' The Journal of Political Philosophy 13(4):377398.

Bunton, R. and Petersen, A. (2005) 'Genetics and governance: An introduction' in R. Bunton and A. Petersen (eds) Genetic Governance: Health, Risk and Ethics in the Biotech Era, pp. 1-27. Routledge: London.

Cameron, C. and Williamson, R. (2003) 'Is there an ethical difference between pre-implantation genetic diagnosis and abortion?' Journal of Medical Ethics 29:90-92.

Chen, E. and Schiffman, J. (2000) 'Attitudes towards genetic counselling and prenatal diagnosis among a group of individuals with physical disabilities' Journal of Genetic Counselling 9(2):137-152. 
Condit, C. (1999) 'How the public understands genetics: Non-deterministic and non-discriminatory interpretations of the "blueprint" metaphor' Public Understandings of Science 8:169-180.

Conrad, P. and Weinberg, D. (1996) 'Has the gene for alcoholism been discovered three times since 1980 ? A news media analysis' Perspectives on Social Problems 8:3-24.

Conrad, P. (1997) 'Public eyes and private genes: Historical frames, news constructions, and social problems' Social Problems 44(2):139-154.

Conrad, P. (1999) 'A mirage of genes' Sociology of Health and Illness 21(2):228-241.

Domingues, J. (2004) 'The future of human nature' European Journal of Social Theory 7(3):405-410.

Ehrich, K.; Williams, C.; Scott, R.; Sandall, J. and Farsides, B. (2006) 'Social welfare, genetic welfare? Boundary-work in the IVF/PGD clinic' Social Science and Medicine 63:1213-1224.

Ettore, E. (1999) 'Experts as 'storytellers' in reproductive genetics: Exploring key issues' Sociology of Health and Illness 21(5):539559.

Ettore, E. (2005) 'The sociology of the new genetics: Conceptualizing the links between reproduction, gender and bodies' in R. Bunton and A. Petersen (eds) Genetic Governance: Health, Risk and Ethics in the Biotech Era, pp. 107-120. Routledge: London.

Finkler, K.; Skrzynia, C. and Evans, J. (2003) 'The new genetics and its consequences for family, kinship, medicine and medical genetics' Social Science and Medicine 57:403-412.

Franklin, S. and Roberts, C. (2006) Born and Made: An Ethnography of Pre-implantation Genetic Diagnosis Princeton University Press: Princeton NJ.

Fukuyama, F. (2003) Our Posthuman Future: Consequences of the Biotechnology Revolution Profile Books: London.

Gavaghan, C. (2003) 'Use of pre-implantation genetic diagnosis to produce tissue donors: An irreconcilable dichotomy' Human Fertility 6:23-25.

Giddens, A. (1990) The Consequences of Modernity Polity Press: Cambridge.

Giddens, A. (1991) Modernity and Self Identity: Self and Society in the Late Modern Age Polity Press: Cambridge.

Gilding, M. (2002) 'Families of the new millennium: Designer babies, cyber sex and virtual communities' Family Matters 62(Winter):4-10.
Gottweis, H. (2005) 'Emerging forms of governance in genomics and post-genomics: Structures, trends, perspectives' in R. Bunton and A. Petersen (eds) Genetic Governance: Health, Risk and Ethics in the Biotech Era, pp. 189-208. Routledge: London.

Habermas, J. (2003) The Future of Human Nature Polity Press: Cambridge.

Habgood, J. (2003) 'A Christian approach to bioethics' Human Fertility 6:137-141.

Helen, I. (2005) 'Risk management and ethics in high-tech antenatal care: The Finnish experience' in R. Bunton and A. Petersen (eds) Genetic Governance: Health, Risk and Ethics in the Biotech Era, pp. 47-63 Routledge: London.

Herbert, M. (2005) 'More than code: From genetic reductionism to complex biological systems' in R. Bunton and A. Petersen (eds) Genetic Governance: Health, Risk and Ethics in the Biotech Era, pp. 171-188. Routledge: London.

Jallinoja, P. (2005) 'Ethics of clinical genetics: The spirit of the profession and trials of suitability from 1970 to 2000' in R. Bunton and A. Petersen (eds) Genetic Governance: Health, Risk and Ethics in the Biotech Era, pp. 3145. Routledge: London.

Jones, O. (2001) 'Controlling consequences of preconception sex selection' The American Journal of Bioethics 1(1):19-21.

Kavoulakso, K. (2004) 'Ruptured formalism: The challenge of bioethics and the limits of moral formalism' Radical Philosophy 125(MayJune):37-45.

Kelly, S. (2005) “"New” genetics meets the old underclass: Findings from a study of genetic outreach services in rural Kentucky' in R. Bunton and A. Petersen (eds) Genetic Governance: Health, Risk and Ethics in the Biotech Era, pp. 137-151. Routledge: London.

Kerr, A. and Cunningham-Burley, S. (2000) 'On ambivalence and risk: Reflexive modernity and the new human genetics' Sociology 34(2):283-304.

Knudsen, S. (2005) 'Communicating novel and conventional scientific metaphors: A study of the development of the metaphor of genetic code' Public Understandings of Science 14:373-392.

Krones, T.; Schluter, E.; Neuwohner, E.; El Ansari, S.; Wissner, T. and Richter, G. (2006) 'What is the pre-implantation embryo?' Social Science and Medicine 63:1-20. 
Lavery, S. (2004) 'Pre-implantation genetic diagnosis and the welfare of the child' Human Fertility 7(4):295-300.

Lemke, T. (2005) 'From eugenics to the government of genetic risk' in R. Bunton and A. Petersen (eds) Genetic Governance: Health, Risk and Ethics in the Biotech Era, pp. 95-105. Routledge: London.

Nerlich, B.; Johnson, S. and Clarke, D. (2003) 'The first "designer baby": The role of narratives, clichés and metaphors in the year 2000 media debate' Science as Culture 12(4):471-498.

Parker, M. (2000) 'Public deliberation and private choice in genetics and reproduction' Journal of Medical Ethics 26:160-165.

Petersen, A. (2001) 'Biofantasies: Genetics and medicine in the print news media' Social Science and Medicine 52:1255-1268.

Petersen, A.; Anderson, A. and Allan, S. (2005) 'Science fiction/science fact: Medical genetics in news stories' New Genetics and Society 24(3):337-353.

Petersen, A. (2006) 'The genetic conception of health: Is it as radical as claimed?' Health: An Interdisciplinary Journal for the Social Study of Health, Illness and Medicine 10(4):481-500.

Petersen, T. (2005) 'Just diagnosis? Preimplantation genetic diagnosis and injustices to disabled people' Journal of Medical Ethics 31:231-234

Pilnick, A. (2002) “"There are no rights and wrongs in these situations": Identifying interactional difficulties in genetic counselling' Sociology of Health and Illness 24(1):66-88.

Polkinghorne, J. (2004) 'The person, the soul, and genetic engineering' Journal of Medical Ethics 30:593-597.

Polzer, J. (2005) 'Choice as responsibility: Genetic testing as citizenship through familial obligation and the management of risk' in $\mathrm{R}$. Bunton and A. Petersen (eds) Genetic Governance: Health, Risk and Ethics in the Biotech Era, pp. 79-92. Routledge: London.

Poutanen, S. (2005) 'The first genetic screening in Finland: Its execution, evaluation and some possible implications for liberal government' in R. Bunton and A. Petersen (eds) Genetic Governance: Health, Risk and Ethics in the Biotech Era, pp. 65-78. Routledge: London.

Rapp, R. (1999) Testing Women, Testing the Fetus: The Social Impact of Amniocentesis in America Routledge: New York.
Rapp, R.; Heath, D. and Taussig, K. (2001) 'Genealogical dis-ease: Where hereditary abnormality, biomedical explanation, and family responsibility meet' in S. Franklin and S. McKinnon (eds) Relative Values:

Reconfiguring Kinship Studies, pp.385-409.

Duke University Press: Durham.

Reame, N. (2001) 'Gender by design: Not yet ready for prime time' American Journal of Bioethics 1(1):29-31.

Rhodes, R. (2001) 'Acceptable sex selection' American Journal of Bioethics 1(1):31-33.

Rixecker, S. (2002) 'Genetic engineering and queer biotechnology: The eugenics of the twenty-first century' Journal of Genocide Research 4(1):109-126.

Roberts, C. and Franklin, S. (2004) 'Experiencing new forms of genetic choice: Findings from an ethnographic study of pre-implantation genetic diagnosis' Human Fertility 7(4):285-293.

Robertson, J. (2001) 'Preconception gender selection' The American Journal of Bioethics $1(1): 2-9$.

Robertson, J. (2003) 'Extending pre-implantation genetic diagnosis: Medical and non-medical uses' Journal of Medical Ethics 29(4):213216.

Rose, N. (2005) 'Will biomedicine transform society? The political, economic, social and personal impact of medical advances in the twenty-first century' in Clifford Barclay Lecture available at http://www.lse.ac.uk/ collections/LSEPublicLecturesAndEvents/pdf/ 20050202-WillBiomedicine-NikRose.pdf.

Rothman, B. (1993) The Tentative Pregnancy: How Amniocentesis Changes the Experience of Motherhood Norton: New York.

Savulescu, J. (2001) 'In defense of selection for nondisease genes' The American Journal of Bioethics 1(1):16-19.

Scambler, G. (2005) 'The future of human nature' Social Theory and Health 3(3):242-244.

Scully, J.; Banks, S. and Shakespeare, T. (2006) 'Chance, choice and control: Lay debate on prenatal social sex selection' Social Science and Medicine 63:21-31.

Shakespeare, T. (1998) 'Choices and rights: Eugenics, genetics and disability equality' Disability and Society 13(5):665-681.

Smith, J. (2003) “"Suitable Mothers”: Lesbian and Single Women and the "Unborn" in 
Australian Parliamentary Discourse' Critical Social Policy 231(74): 63-88.

Watt, H. (2004) 'Pre-implantation genetic diagnosis: Choosing the "good enough" child Health Care Analysis 12(1):51-60.

Ward, L. (2005) 'Whose right to choose? The new genetics, prenatal testing and people with learning difficulties' in R. Bunton and A. Petersen (eds) Genetic Governance: Health, Risk and Ethics in the Biotech Era, pp. 121135. Routledge: London.
Willis, E. (2005) 'Public health and the "new genetics": Balancing individual and collective outcomes' in R. Bunton and A. Petersen (eds) Genetic Governance: Health, Risk and Ethics in the Biotech Era, pp. 155-169. Routledge: London.

Zeiler, K. (2004) 'Reproductive autonomous choice - A cherished illusion? Reproductive autonomy examined in the context of preimplantation genetic diagnosis' Medicine, Health Care and Philosophy 7(2):175-183.

\title{
ANNOUNCING — VOLUME 1 (2007)
}

\author{
International Journal of Multiple Research Approaches \\ ISSN 1834-0846 (Print) ISSN 1834-0814 (Online) \\ Editor-in-Chief: Professor Carol Grbich, Flinders University School of Medicine \\ Manuscript submissions to: MRAeditorial@e-contentmanagement.com
}

The International Journal of Multiple Research Approaches (ISSN 1834-0806) is an international peerreviewed journal for timely publication of research, scholarship, educational, researcher and practitioner perspectives on multiple, hybrid (outcome of unusual blending), synergistic (combined effect), integrated and cultural research approaches - be these indigenous, institutional, or community based - and including the Asian, Pacific, Latin American and African regions as well as Europe and North America. The focus is on combining or synergising various theoretical frame-works, methodologies and methods most appropriate for addressing research questions.

In one forum, the International Journal of Multiple Research Approaches (ISSN 1834-0806) covers:

- Multiple, hybrid, synergistic, integrated, cultural, mixed qualitative and quantitative empirical research approaches.

- Theoretical and conceptual articles on methodological and ethical dilemmas and advances

- Critical perspectives and proposals for management of technical issues (eg, software development and data handling).

- Discussion of philosophical issues, practical problems and benefits associated with multiple, hybrid, synergistic, integrated and cultural approaches including theoretical frameworks, methodologies, data collection, management and analysis methods and different forms of transformation and representation.

- Literature reviews - including those from theses - on methodological trends/advances.

- Articles on methodology education, technologies and learning techniques.

- Practitioner perspectives, experiences from the field and case applications of methodologies and results.

Article formats include, but are not restricted to, traditional academic research articles, research design, case applications, literature reviews, approaches to teaching and learning, software advances and constraints, practitioner perspectives and advice for novice researchers. Original articles informing multiple and mixed methodological research and practice are encouraged from a range health sciences, social sciences, arts and organizational sciences disciplines including, but not limited to: anthropology, criminology, Indigenous and cultural studies, management, marketing, economics, development studies, psychology, education, political science, geography, history, psychology, nursing, social work, public policy, philosophy and related disciplines.

Manuscripts, prepared according to APA $5^{\text {th }}$ edition Author Guidelines, should be submitted to: MRAeditorial@e-contentmanagement.com

Published by eContent Management Pty Ltd (SAN 902-4964) PO Box 1027, Maleny, QLD 4552, Australia Tel. +61-7-5435 2900; Fax: +61-7-5435 2911 